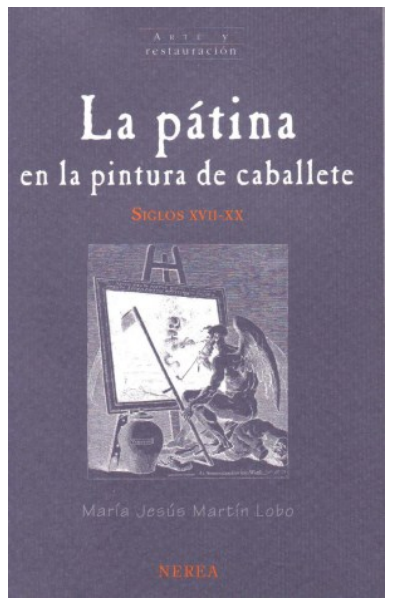

\title{
La pátina en la pintura de caballete. Siglos XVII-XX
}

María Jesús Martín Lobo

Editorial Nerea, S.A.

Col. Arte y restauración

Donostia-San Sebastián, 2009

220 páginas, 16 figuras, $23,5 \times 15 \mathrm{~cm}$.

ISBN: 978-84-96431-54-6

Este título pertenece a la colección "Arte y restauración” de la Editorial Nerea que, además de las traducciones al castellano de los libros italianos de Nardini -col. Arte e restauro-, incluye en su catálogo nuevas producciones españolas como es el caso del libro ahora reseñado.

La controversia y discusión sobre la función desempeñada por la pátina en las obras pictóricas ha sido constante en la historia de la conservación. El libro de María Jesús Martín Lobo supone una nueva aportación, en castellano, en esta línea de investigación. Sus páginas enfocan el papel de la pátina a través del tiempo y con qué intención ha sido interpretada en las pinturas de unos y otros siglos. Múltiples referencias documentales permiten a la autora mostrar las opiniones de tratadistas, artistas y críticos, configurando de esta manera un amplio abanico de opiniones favorables o negativa respecto a su efecto.

El libro sigue un orden cronológico y se inicia dando a conocer la etimología de la palabra pátina, su evolución semántica, su aplicación a los metales y a la pintura. También se detiene en la aparición del término en España en el siglo XVIII. Recorre brevemente los antecedentes de las polémicas sobre las limpiezas y la eliminación de las pátinas durante el Renacimiento. Después desarrolla con mayor profundidad la situación durante el siglo XVII, prestando especial atención a las ideas positivas del "Tiempo pintor". En esta parte analiza a dos autores: Filippo Baldinucci y Marco Boschini. En aquella época, el mayor aprecio del público por los efectos causados por el paso del tiempo dio lugar a la introducción de falsas pátinas en el comercio de la pintura, convirtiéndose en un recurso frecuente por parte de falsificadores e imitadores de pintores antiguos, como Pietro della Vecchia.

La autora se extiende con más amplitud en el siglo XVIII. El capítulo denominado "La pátina es sometida a análisis" lo dedica a los primeros intentos de darle una explicación científica a la degradación, a los efectos de las preparaciones coloreadas y al papel de los aceites y del barniz. Seguidamente pone en relación el gusto y la pátina, contraponiendo las ideas de Joseph Adison sobre el "tiempo pintor", con las de William Hogarth y el "tiempo destructor". En estas páginas presenta interesantes citas de Milizia sobre la alteración de los colores y el efecto del paso del tiempo por las pinturas. También aborda el problema del tratamiento de la pátina en los talleres de restauración italianos, destacando algunas figuras como Luigi Crespi, Andrea Pasta, Pietro Edwards y Philipp Hackert. Casos precedidos por la actuación de Maratta, al que defendió Bellori que alabó la idea de ripristino, basándose en un concepto neoplatónico, en el que la imagen prevalece como encarnación de una idea del artista, frente a la materia que la conforma. Termina ese siglo explicando la situación en España, en la que destacan las ideas de Antonio Ponz, García de la Huerta y Preciado de la Vega. 
El recorrido continúa en el capítulo dedicado al siglo XIX y a los "Nuevos significados para el término pátina". Un nuevo concepto de pátina se utilizará con fines estéticos en las limpiezas y esto se refleja en los pioneros manuales de restauración. En primer lugar, la autora se refiere a dichos textos así como a las polémicas que surgieron sobre las limpiezas en los museos, con los ejemplos de la National Gallery de Londres, la Pinacoteca de Munich y el Louvre. También en este siglo destacan los tratamientos con aplicación de pátinas artificiales, deteniéndose en los ejemplos de Secco Suardo y del "barniz de galería" utilizado en Inglaterra. En España alude a los textos de Vicente Poleró y Mariano de la Roca y Delgado, así como a los casos menos conocidos de Jerónimo Gómez Rodríguez y Saturnino Cervera y Lacour. Termina exponiendo las críticas que recibe el Museo del Prado en tiempos de José de Madrazo.

$\mathrm{Al}$ adentrarse en el siglo XX relata la controversia del año 1947 sobre las limpiezas de la National Gallery. Los nuevos planteamientos científicos y críticos obligan a una revisión del concepto de pátina. Se exponen las opiniones de las dos figuras principales de este periodo: Cesare Brandi y Paul Philippot. Y dedica el último capítulo a Alessandro Conti, otra figura cuyas referencias también están presentes a lo largo de todo el libro.

Ana Calvo Manuel

Escola das Artes, UCP, Oporto

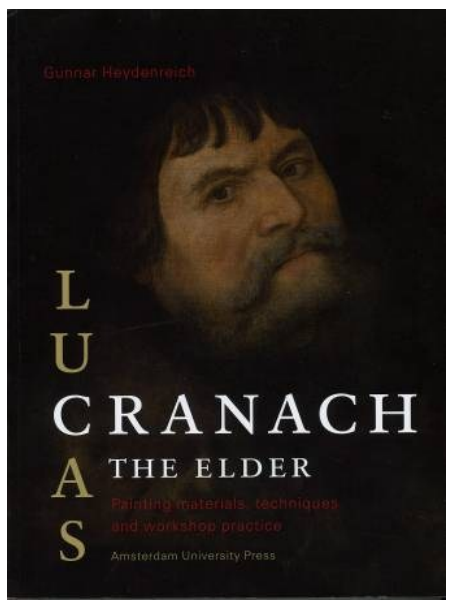

Lucas Cranach the Elder. Painting materials, techniques and workshop practice

Gunnar Heydenreich

Editorial Amsterdam University Press

Amsterdam, 2007

464 páginas, 277 figuras, $25 \times 19 \mathrm{~cm}$.

ISBN: 1397890533567456

Este libro presenta el primer estudio detallado de las prácticas de trabajo y los materiales utilizados por uno de los más grandes artistas de la Europa del siglo XVI, Lucas Cranach el Viejo.

El autor, Gunnar Heydenreich ha examinado numerosos cuadros complementando los datos suministrados por medio de los métodos de análisis instrumentales más actuales con una amplia gama de fuentes documentales. Todo ello hace que proporcione una visión fascinante de la práctica diaria del pintor, la organización de su estudio, y la relación entre los contratos y comitentes con los materiales, las técnicas y las formas de expresión artística.

En su parte inicial, presenta una información detallada sobre el uso de soportes de Cranach en la pintura, incluyendo la normalización de los formatos y las prácticas de construcción de los paneles. Continúa con el análisis de las capas de preparación las capas de aislamiento, la forma de hacer el dibujo subyacente. Posteriormente refiere la gran riqueza de pigmentos diferentes de su paleta 